\title{
EVALUASI KINERJA POSDAYA SEBAGAI PROGRAM PEMBERDAYAAN MASYARAKAT
}

\author{
Pudji Muljono $^{1}$, Dwi Sadono ${ }^{1}$ dan Burhanuddin ${ }^{2}$ \\ ${ }^{1}$ Dept. SKPM, Fakultas Ekologi Manusia IPB Bogor \\ ${ }^{2}$ Dept. Agribisnis, Fakultas Ekonomi Manajemen IPB Bogor \\ E-mail: pudjimuljono@gmail.com
}

\begin{abstract}
ABSTRAK. Penelitian ini bertujuan: (1)melakukan evaluasi kinerja Posdaya dalam bidang pendidikan, ekonomi, kesehatan dan lingkungan; (2) mengkaji faktor pendukung dan penghambat perkembangan Posdaya.Unit penelitian ini adalah Posdaya yang merupakan lembaga pemberdayaan di tingkat komunitas. Data penelitian dikumpulkan dengan angket/kuesioner dan wawancara kelompok terhadap para pengurus dan kader Posdaya. Analisis data dilakukan dengan statistik deskriptif dan analisis SWOT. Hasil evaluasi kinerja terhadap 20 Posdaya di wilayah Kota Bogor dan Kabupaten Bogor menunjukkan bahwakinerja Posdaya tergolong cukup baik. Perlu dilakukan pembinaan lebih lanjut terhadap Posdaya yang masih lemah kinerjanya, baik dalam aspek kesekretariatan, kemitraan, pendidikan, ekonomi, kesehatan, maupun aspek lingkungan.
\end{abstract}

Kata kunci: kinerja; pemberdayaan masyarakat; Posdaya.

\section{PERFORMANCE EVALUATION OF POSDAYA AS COMMUNITY EMPOWERMENT PROGRAME}

ABSTRACT. This study aims: (1) to evaluate the Posday a performance in the areas of education, economy, health and environment; (2) to examine the supporting and inhibiting factors of Posdaya development. Theresearch unitis Posdaya which is the institutional empowermentat the community level. Data were collected by questionnaire/questionnaire and group interviews to the managers and cadres of Posdaya. Data was analyzed using descriptive statistics and SWOT analysis techniques. The results of the performance evaluation of 20 Posdayain the city of Bogor and Bogor show that Posdaya performance, capacity and effective ness of support cadre is quite good. Need to be developed further toPosdaya weak performance, both in terms of secretarial, partnerships, education, economy, health, andenvironmental aspects.

Key words: performance; community empowerment; Posdaya.

\section{PENDAHULUAN}

Peningkatan kualitas manusia sebagai sumber daya pembangunan merupakan prasyarat utama untuk memperbaiki derajat kesejahteraan rakyat. Tujuan utama pembangunan millenium atau Millenium Development Goals (MDGs) di Indonesia, dengan prioritas pengentasan kemiskinan, menetapkan proporsi penduduk miskin pada tahun 2015 diturunkan 50\% dari $16,4 \%$ menjadi $8,2 \%$. Keputusan itu merupakan tekad dan kebijaksanaan pemerintah yang perlu didukung semua instansi dan institusi pembangunan. Agar upaya itu berhasil dengan baik perlu diikuti pengembangan gerakan pemberdayaan keluarga yang dilaksanakan secara intensif. Pembangunan ekonomi yang akan menghasilkan pertumbuhan ekonomi perlu melibatkan partisipasi masyarakat agar pembangunan yang dilakukan seimbang dan mencapai sasaran. Pembangunan ekonomi harus diimbangi dengan peningkatan partisipasi sosial. Advokasi sosial juga perlu dilakukan agar komitmen pembangunan lebih kuat (Suyono, 2007).

Partisipasi masyarakat dalam kegiatan pembangunan akan terwujud apabila dilakukan upaya pengembangan dan pemberdayaan masyarakat sesuai potensi dan kemampuannya. Menurut Suharto (2005) pemberdayaan menunjuk pada kemampuan orang/ kelompok/masyarakat yang rentan dan lemah, sehingga mereka memiliki kekuatan atau kemampuan dalam: a) memenuhi kebutuhan dasarnya sehingga mereka memiliki kebebasan (freedom), dalam arti bukan saja bebas mengemukakan pendapat, melainkan bebas dari kelaparan, kebodohan dan kesakitan, b) menjangkau sumber-sumber produktif yang memungkinkan mereka dapat meningkatkan pendapatannya dan memperoleh barang-barang dan jasa-jasa yang mereka perlukan, c) berpartisipasi dalam proses pembangunan dan keputusankeputusan yang mempengaruhi mereka.

Karakteristik masyarakat yang telah berdaya menurut Sumarjo dan Saharuddin (2004) adalah sebagai berikut: a) mampu memahami diri dan potensinya, b) mampu merencanakan (mengantisipasi kondisi perubahan ke depan) dan mengarahkan dirinya sendiri, c) memiliki kekuatan untuk berunding dan bekerjasama secara saling menguntungkan dengan "bargaining power" yang memadai, d) bertanggung jawab atas tindakan sendiri.

Posdaya merupakan gagasan baru guna menyambut anjuran pemerintah untuk membangun sumberdaya manusia melalui partisipasi keluarga secara aktif. Proses pemberdayaan itu diprioritaskan pada peningkatan kemampuan keluarga untuk bekerja keras mengentaskan kebodohan, kemalasan dan kemiskinan dalam arti yang luas. Sasaran kegiatan yang dituju adalah terselenggarakannya upaya bersama agar setiap keluarga mempunyai kemampuan melaksanakan delapan fungsi keluarga. Posdaya adalah forum silaturahmi, 
advokasi, komunikasi, informasi, edukasi dan sekaligus bisa dikembangkan menjadi wadah koordinasi kegiatan penguatan fungsi-fungsi kekeluargaan secara terpadu. Penguatan fungsi-fungsi utama tersebut diharapkan memungkinkan setiap keluarga semakin mampu membangun dirinya menjadi keluarga sejahtera, keluarga yang mandiri dan keluarga yang sanggup menghadapi tantangan masa depan dengan lebih baik (Suyono dan Haryanto, 2009).

Pengembangan Posdaya ditujukan untuk mencapai hal-hal sebagai berikut: (a) Dihidupkannya dukungan sosial budaya atau social capital seperti hidup gotong royong dalam masyarakat untuk menolong keluarga lain, membantu pemberdayaan secara terpadu atau bersama-sama memecahkan masalah kehidupan yang komplek, melalui wadah atau forum yang memberi kesempatan para keluarga untuk saling asah, asih, dan asuh, dalam memenuhi kebutuhan membangun keluarga bahagia dan sejahtera; (b) Terpeliharanya infrastruktur sosial kemasyarakatan yang terkecil dan solid, yaitu keluarga, yang dapat menjadi perekat atau kohesi sosial, sehingga tercipta suatu kehidupan yang rukun, damai dan memiliki dinamika yang tinggi; (c) Terbentuknya lembaga sosial dengan keanggotaan dan partisipasi keluarga di desa atau kelurahan yang dinamis dan menjadi wadah atau wahana partisipasi sosial, di mana para keluarga dapat memberi dan menerima pembaharuan yang dapat membantu proses pembangunan kehidupan keluarga dengan mulus dan sejuk (Muljono dkk, 2009).

Berdasarkan hasil penelitiannya, Muljono (2011) menyatakan bahwa Posdaya dikembangkan untuk merespon program pemerintah dalam membangun sumber daya manusia melalui partisipasi aktif dalam keluarga. Proses pemberdayaan yang memprioritaskan peningkatan kemampuan keluarga untuk bekerja keras menghilangkan kebodohan, kemalasan dan kemiskinan dalam arti yang luas. Untuk pengembangan Posdaya, Muljono (2010) menyatakan bahwa perlu penegasan kembali tujuan Posdaya, penyegaran anggota dan kader Posdaya, mengintensifkan kegiatan sosialisasi Posdaya kepada semua pihak, seperti masyarakat, tokoh masyarakat, desa, pejabat kabupaten dan pemerintah daerah serta membangun jaringan usaha produktif dalam upaya pemberdayaan masyarakat.

Hasil penelitian menunjukkan bahwa para pemimpin masyarakat dan kader Posdaya menyadari tentang keberadaan Posdaya serta fungsi dan pentingnya Posdaya bagi pemberdayaan masyarakat(Muljono, 2013a). Melalui penelitian lainnya, Muljono (2013b) menyatakan bahwa pemahaman masyarakat tentang Posdaya cukup baik dan mereka harus ditingkatkan kepeduliannya tentang apa dan bagaimana Posdaya. Namunsebagian masyarakat belum sepenuhnya mendukung Posdaya, karena program belum direalisasikan secara konkret.

Hasil penelitian Sadono, Saharuddin dan Yusalina
(2014) menunjukkan bahwa pendampingan Posdaya telah mampu meningkatkan kemampuan pengurus dalam mengelola dan memajukan Posdaya. Sementara itu, penelitian Suwito (2014) yang menganalisis pengaruh kepemimpinan, tata pemerintahan dan etika pemerintahan terhadap efektivitas pemberdayaan dan dampaknya pada kesejahteraan keluarga miskin, menunjukkan bahwa ketiga peubah tersebut memiliki pengaruh yang signifikan.

Penelitian yang dilakukan oleh Saleh, Rokhani dan Bahtiar (2014) tentang hubungan dukungan eksternal dan kewirausahaan terhadap modal sosial melalui model Posdaya menunjukkan hasil bahwa pengembangan modal sosial dan kewirausahaan menghadapi berbagai permasalahan di antaranya kondisi sumber daya manusia, program yang direncanakan dan pendampingan.

Kelembagaan Posdaya cukup potensial dikembangkan menjadi wadah koordinasi kegiatan penguatan fungsi-fungsi keluarga secara terpadu pada komunitas tertentu. Di Indonesia saat ini terdapat lebih dari 40.000 Posdaya yang diinisiasi dan dikembangkan oleh masyarakat dengan pendampingan oleh perguruan tinggi, pemerintah daerah, maupun swasta (YDSM, 2015). Mengingat perkembangan Posdaya yang cukup baik, maka perlu dan sangat relevan untuk dilakukan satu penelitian tentang evaluasi kinerja Posdaya. Hal ini akan sangat bermanfaat untuk melakukan pembinaan lebih lanjut terhadap pemberdayaan masyarakat melalui Posdaya.

Pertanyaan umum dalam kajian ini adalah bagaimana kinerja Posdaya sebagai program pemberdayaan masyarakat, dan faktor apa saja yang mendukung dan menghambat perkembangan Posdaya. Sesuai permasalahan penelitian tersebut, maka penelitian ini bertujuan untuk: (1) mengevaluasi kinerja Posdaya dalam bidang pendidikan, ekonomi, kesehatan dan lingkungan; (2) mengkaji faktor pendukung dan penghambat perkembangan Posdaya.

\section{METODE}

Penelitian ini dilakukan pada 20 Posdaya yang terletak di wilayah Kota Bogor (11 Posdaya) dan Kabupaten Bogor (9 Posdaya). Pemilihan Posdaya yang dijadikan sampel dilakukan secara purposif, yakni semua Posdaya binaan inti yang selama ini telah memperoleh pendampingan oleh Pusat Pengembangan Sumberdaya Manusia (P2SDM)-LPPM IPB bekerjasama dengan pemerintah daerah Kota Bogor dan Kabupaten Bogor. Sebaran jumlah Posdaya yang menjadi sampel kajian evaluasi kinerja Posdaya tersaji pada Tabel 1.

Pelaksanaan penelitian dilakukan dengan mixed method yakni menggabungkan metode kuantitatif dan metode kualitatif (Babbie, 1992; Muljono, 2012). Data penelitian dikumpulkan dengan angket/kuesioner, indepth interview dan FGD. Responden penelitian 
Tabel 1. Jumlah Posdaya Sampel sesuai Sebaran Wilayah Pengamatan

\begin{tabular}{cclcc}
\hline No & $\begin{array}{c}\text { Kabupaten/ } \\
\text { Kota }\end{array}$ & \multicolumn{1}{c}{ Kecamatan } & $\begin{array}{c}\text { Jumlah } \\
\text { Posdaya Sampel }\end{array}$ \\
\hline 1 & Kabupaten & Ciampea & 1 & \\
& Bogor & Cibungbulang & 2 & 9 \\
& & Dramaga & 6 & \\
2 & \multirow{2}{*}{ Kota Bogor } & Bogor Barat & 8 & \\
& & Bogor Selatan & 1 & 11 \\
& & Bogor Timur & 1 & \\
& & Tanah Sareal & 1 & \\
\hline \multicolumn{3}{c}{ Jumlah } & 20 \\
\hline
\end{tabular}

ini adalah para pengurus Posdaya, penggiat (kader) Posdaya yang meliputi kader bidang ekonomi, kader bidang pendidikan, kader bidang kesehatan dan kader bidang lingkungan, serta pendamping Posdaya.

Informasi yang dikumpulkan melalui angket/ kuesioner antara lain tentang identitas Posdaya, program kemitraan atau kerjasama yang telah dilakukan Posdaya, kegiatan bidang pendidikan (PAUD, TK/TKA, kejar Paket $\mathrm{A} / \mathrm{B} / \mathrm{C}$, pelatihan, dll), kegiatan bidang ekonomi (pengembangan usaha, LKM, peminjaman, dll), kegiatan bidang kesehatan (Posyandu, Posbindu, senam sehat, dll), dan kegiatan bidang lingkungan (pengelolaan sampah, pembuatan pupuk kandang, kebersihan lingkungan, dll).

Sebelum dilakukan pengumpulan data, dilakukan pelatihan terhadap enumerator (pelaksana pengumpulan data) agar proses pengumpulan data berlangsung dengan lancar. Guna memperlancar proses pengumpulan data, dilakukan koordinasi dengan para pengurus dan kader Posdaya yang akan menjadi objek kajian.

\section{Teknik Analisis Data}

Analisis data dilakukan secara deskriptif dan analisis SWOT. Untuk perumusan strategi pemberdayaan masyarakat digunakan analisis strenghts, weakness, opportunity and threats (SWOT). Analisis SWOT dilakukan untuk membandingkan faktor eksternal peluang dan ancaman dengan faktor internal kekuatan dan kelemahan yang dihadapi Posdaya sebagai model pemberdayaan masyarakat. Dalam hal ini dilakukan evaluasi faktor internal atau Internal Factors Analysis Summary (IFAS) dan evaluasi faktor eksternal atau Eksternal Factors Analysis Summary (EFAS). Unsurunsur SWOT diberi bobot (nilai) kemudian dihubungkan untuk memperoleh beberapa alternatif strategi dengan rangking tertinggi merupakan alternatif strategi pengembangan Posdaya di masa yang akan datang.

\section{HASIL DAN PEMBAHASAN}

Pada bagian ini dibahas tentang kinerja Posdaya serta evaluasi kinerja Posdaya pada berbagai aspek meliputi aspek kesekretariatan, kemitraan, pendidikan, ekonomi, kesehatan dan lingkungan dengan menggunakan analisis SWOT. Kegiatan evaluasi kinerja Posdaya dilakukan dalam rangka untuk meningkatkan kualitas program pemberdayaan masyarakat, paling tidak di wilayah di mana Posdaya tersebut telah terbentuk.

\section{Kinerja Posdaya}

Evaluasi kinerja Posdaya yang dikaji pada penelitian ini meliputi berbagai aspek yaitu aspek kesekretariatan, kemitraan, pendidikan, ekonomi, kesehatan dan aspek lingkungan. Secara deskriptif berikut ini disajikan uraian bagaimana kinerja Posdaya pada masingmasing aspek tersebut.

Hasil evaluasi kinerja Posdaya yang diperoleh dari akumulasi jumlah skor kinerja Posdaya untuk setiap aspek yang dinilai, yaitu aspek kesekretariatan, aspek kemitraan, aspek pendidikan, aspek ekonomi, aspek kesehatan, dan aspek lingkungan. Secara lengkap rataan skor untuk setiap aspek dapat dilihat pada Tabel 2. Berdasarkan tabel tersebut, maka dapat disimpulkan bahwa capaian kinerja kegiatan Posdaya secara keseluruhan adalah tergolong cukup baik, namun pada kondisi lain tergolong kurang lancar dengan rataan skor 2,61.

Tabel 2. Rataan Skor Kinerja Kegiatan Posdaya Secara Keseluruhan

\begin{tabular}{llcc}
\hline & Aspek yang Dinilai & Rataan Skor & Keterangan \\
\hline 1. & Kesekretariatan & 3,10 & Cukup Baik \\
2. & Kemitraan/Kerjasama & 1,86 & Kurang Baik \\
3. & Pendidikan & 2,74 & Cukup Baik \\
4. & Ekonomi & 2,62 & Cukup Baik \\
5. & Kesehatan & 3,32 & Cukup Baik \\
6. & Lingkungan & 2,00 & Kurang Baik \\
\hline & Total Rataan Skor & 2,61 & Cukup Baik \\
\hline
\end{tabular}

Dari keenam aspek yang dinilai terkait capaian kegiatan Posdaya, ternyata aspek kesehatan yang memiliki nilai rataan skor tertinggi $(3,32)$ dan tergolong cukup baik. Selain aspek kesehatan, kinerja Posdaya yang tergolong cukup baik adalah aspek kesekretariatan, pendidikan dan ekonomi. Sementara dua aspek lainnya, yakni aspek kerjasama dan lingkungan tergolong kurang baik. Kinerja aspek kesehatan Posdaya termasuk cukup baik, memang terbukti di lapangan yakni dengan terlaksananya kegiatan Posyandu, Posbindu, senam sehat, dan program kesehatan lainnya di Posdaya yang menjadi lokasi kajian.

\section{Analisis SWOT Kinerja Posdaya}

Untuk menentukan strategi yang tepat dalam menerapkan analisis kedepan terkait perkembangan posdaya, maka terlebih dahulu harus diketahui faktorfaktor yang menjadi kekuatan (strengths), kelemahan (weakness), peluang (opportunities), dan ancaman (threats). Setelah diketahui faktor-faktor yang 
mempengaruhi keefektifan, maka langkah selanjutnya adalah menganalisis data yang ada menjadi dua matriks, yaitu matriks IFAS (Internal Factors Analysis Summary) dan matriks EFAS (External Factor Analysis Summary).

Berdasarkan hasil analisis IFAS dan EFAS terhadap empat bidang kegiatan Posdaya. Hasil analisis SWOT dengan matriks IFAS dan EFAS terhadap empat bidang kegiatan Posdaya adalah sebagai berikut.

\section{Analisis Kinerja Bidang Ekonomi}

Berikut disajikan matriks IFAS dan EFAS kegiatan Posdaya bidang ekonomi seperti pada Tabel 3 dan 4 berikut.

Berdasarkan hasil yang didapat dari analisis IFAS dan EFAS pada Tabel 3 dan 4 tersebut, hasilnya dapat dirangkum sebagai berikut: skor total kekuatan 2,07; skor total kelemahan 2,18; skor total peluang 2,83; dan skor total ancaman 1,57.Dari hasil perhitungan di atas, dalam analisis strateginya memerlukan penegasan dari adanya posisi dalam salib sumbu yaitu antara kekuatan dan kelemahan, maupun peluang dan ancaman yang kesemuanya digambarkan dalam garis positif dan negatif. Hal ini mengakibatkan, skor total kekuatan tetap 2,07, skor total kelemahan menjadi $-2,18$ sedangkan skor total peluang 2.83, dan skor total ancaman menjadi -1,57.

Dari analisis tersebut di atas bahwasanya faktor kekuatan lebih kecil dari faktor kelemahan dan pengaruh dari faktor peluang lebih besar dari faktor ancaman. Berdasarkan hasil analisis diperoleh nilai IFAS (S

Tabel 3. Hasil Matriks IFAS Kinerja Posdaya Bidang Ekonomi

\begin{tabular}{|c|c|c|c|c|}
\hline No & $\begin{array}{l}\text { Faktor-Faktor Strategis } \\
\text { Internal }\end{array}$ & Bobot & Rating & Nilai \\
\hline & \multicolumn{4}{|l|}{ Kekuatan (Strenghts) } \\
\hline & $\begin{array}{l}\text { Tersedianya tenaga kerja } \\
\text { yang cukup }\end{array}$ & 0,11 & 4 & 0,45 \\
\hline & Kelompok Arisan & 0,10 & 4 & 0,40 \\
\hline & $\begin{array}{l}\text { Bermitra dengan perusahaan } \\
\text { besar }\end{array}$ & 0,12 & 5 & 0,60 \\
\hline & $\begin{array}{l}\text { Kegiatan usaha berbasis } \\
\text { sumberdaya lokal }\end{array}$ & 0,12 & 5 & 0,62 \\
\hline & Total Strenghts & & & 2,07 \\
\hline & \multicolumn{4}{|l|}{ Kelemahan (Weakness) } \\
\hline & $\begin{array}{l}\text { Usahanya belum dikenal } \\
\text { pasar }\end{array}$ & 0,10 & 4 & 0,39 \\
\hline & $\begin{array}{l}\text { Pelibatan donatur atau } \\
\text { investor terbatas }\end{array}$ & 0,11 & 4 & 0,45 \\
\hline & $\begin{array}{l}\text { Tersendatnya pengembangan } \\
\text { UKM ibu/wanita }\end{array}$ & 0,12 & 4 & 0,46 \\
\hline & $\begin{array}{l}\text { Besarnya tanggungan } \\
\text { keluarga }\end{array}$ & 0,11 & 4 & 0,44 \\
\hline & $\begin{array}{l}\text { Tidak memiliki tabungan } \\
\text { dan asset }\end{array}$ & 0,11 & 4 & 0,44 \\
\hline & Total Weakness & & & 2,18 \\
\hline & Selisih $\mathbf{S}-\mathbf{W}$ & & & $-0,11$ \\
\hline
\end{tabular}

$-\mathrm{W})$ yaitu $2,07-2,18=-0,11$ dan nilai EFAS $(\mathrm{O}-$ T) yaitu $2,83-1,57=1,26$. Dari hasil tersebut dapat digambarkan letak posisi kegiatan bidang ekonomi pada analisis SWOT seperti pada Gambar 1.

Tabel 4. Hasil Matriks EFAS Kinerja Posdaya Bidang Ekonomi

\begin{tabular}{|c|c|c|c|c|}
\hline No & $\begin{array}{c}\text { Faktor-Faktor Strategis } \\
\text { Eksternal Peluang } \\
\text { (Opportunities) }\end{array}$ & Bobot & Rating & Nilai \\
\hline & $\begin{array}{l}\text { Menciptakan perubahan } \\
\text { ekonomi positif di } \\
\text { masyarakat }\end{array}$ & 0,11 & 5 & 0,54 \\
\hline & Naiknya harga-harga & 0,06 & 3 & 0,19 \\
\hline & $\begin{array}{l}\text { Kebijakan pemberdayaan } \\
\text { ekonomi pemerintah daerah }\end{array}$ & 0,10 & 5 & 0,50 \\
\hline & $\begin{array}{l}\text { Program pengembangan } \\
\text { usaha mikro/kecil }\end{array}$ & 0,10 & 5 & 0,52 \\
\hline & $\begin{array}{l}\text { Lembaga keuangan yang pro } \\
\text { masyarakat miskin }\end{array}$ & 0,11 & 5 & 0,54 \\
\hline & $\begin{array}{l}\text { Program pengentasan } \\
\text { kemiskinan oleh pemerintah }\end{array}$ & 0,11 & 5 & 0,53 \\
\hline & Total Opportunities & & & 2,83 \\
\hline \multicolumn{5}{|c|}{ Ancaman (Threats) } \\
\hline & $\begin{array}{l}\text { Masuknya produk impor } \\
\text { dengan harga murah }\end{array}$ & 0,08 & 4 & 0,32 \\
\hline & $\begin{array}{l}\text { Harga produk pertanian } \\
\text { murah }\end{array}$ & 0,09 & 4 & 0,36 \\
\hline & $\begin{array}{l}\text { Daya beli masyarakat } \\
\text { menurun }\end{array}$ & 0,08 & 4 & 0,33 \\
\hline & $\begin{array}{l}\text { Disparitas/kesenjangan } \\
\text { ekonomi antar wilayah }\end{array}$ & 0,07 & 3 & 0,21 \\
\hline & Tingginya bunga bank & 0,09 & 4 & 0,34 \\
\hline & Total Threats & & & 1,57 \\
\hline & Selisih $\mathrm{O}-\mathrm{T}$ & & & 1,26 \\
\hline
\end{tabular}

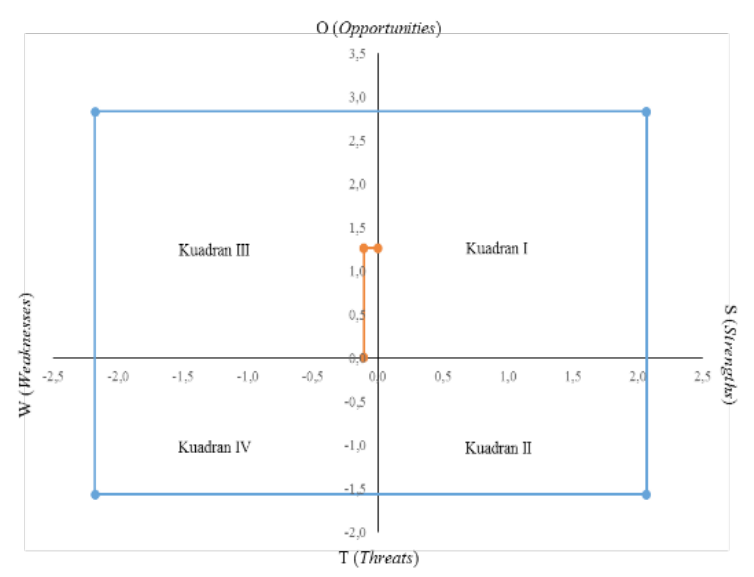

Gambar 1. Hasil Diagram Analisis SWOT Kinerja Posdaya Bidang Ekonomi

Dilihat dari Gambar 1, posisi kegiatan Posdaya bidang ekonomi berada pada kuadran ke-3 di mana kegiatan Posdaya bidang ekonomi pada kuadran ini meskipun menghadapi berbagai kelemahan dari segi internal, namun kegiatan Posdaya bidang ekonomi ini masih memiliki peluang yang besar dari segi eksternal. Meskipun kegiatan Posdaya bidang ekonomi masih 
lemah namun sangat berpeluang, di mana produk Posdaya sebagian sudah layak pasar namun terkendala dengan kemasan yang belum layak. Oleh karena itu, arah dan strategi kegiatan Posdaya bidang ekonomi yang sesuai adalah perbaikan kondisi internal, misalnya stabilisasi dan rasionalisasi program pengem-bangan usaha kecil/mikro, pengembangan lembaga keuangan pro masyarakat miskin, meningkatkan jumlah donatur atau investor untuk pengembangan ekonomi pro rakyat miskin dan sebagainya.

\section{Analisis Kinerja BidangPendidikan}

Berikut disajikan matriks IFAS dan EFAS kegiatan Posdaya bidang pendidikan seperti pada Tabel 5 dan 6 berikut.

Tabel 5. Hasil Matriks IFAS Kinerja Posdaya Bidang Pendidikan

\begin{tabular}{|c|c|c|c|c|}
\hline No & $\begin{array}{l}\text { Faktor-Faktor Strategis } \\
\text { Internal }\end{array}$ & Bobot & Rating & Nilai \\
\hline & \multicolumn{4}{|l|}{ Kekuatan (Strenghts) } \\
\hline & $\begin{array}{l}\text { Selalu ada kader tangguh } \\
\text { dan terampil }\end{array}$ & 0,11 & 5 & 0,53 \\
\hline & Ketersediaan guru & 0,11 & 5 & 0,55 \\
\hline & Fasilitas taman bacaan & 0,11 & 5 & 0,53 \\
\hline & Fasilitas belajar mengajar & 0,11 & 5 & 0,55 \\
\hline & Ketersediaan kurikulum & 0,11 & 5 & 0,53 \\
\hline & Total Strenghts & & & 2,69 \\
\hline & \multicolumn{4}{|l|}{ Kelemahan (Weakness) } \\
\hline & $\begin{array}{l}\text { Soft skills SDM posdaya } \\
\text { masih rendah }\end{array}$ & 0,10 & 4 & 0,40 \\
\hline & $\begin{array}{l}\text { Kaderisasi pengurus tidak } \\
\text { berjalan }\end{array}$ & 0,09 & 4 & 0,37 \\
\hline & $\begin{array}{l}\text { Belum semua warga } \\
\text { mengenal dan memahami } \\
\text { posdaya }\end{array}$ & 0,10 & 4 & 0,39 \\
\hline & $\begin{array}{l}\text { Belum adanya jadwal } \\
\text { pertemuan koordinasi }\end{array}$ & 0,08 & 4 & 0,34 \\
\hline & $\begin{array}{l}\text { Kurangnya inisiatif untuk } \\
\text { melakukan konsultasi }\end{array}$ & 0,09 & 4 & 0,36 \\
\hline & Total Weakness & & & 1,85 \\
\hline & Selisih $S-W$ & & & 0,84 \\
\hline
\end{tabular}

Berdasarkan analisis IFAS, nilai total faktor internal yang diperoleh adalah 0,84 . lebih besar dari 0,81 yang merupakan nilai rata-rata. Hal ini memberikan gambaran bahwa keadaan internal Posdaya bidang pendidikan sebenarnya dapat mengatasi berbagai permasalahan internal kegiatan-kegiatan Posdaya bidang pendidikan.

Pada faktor eksternal, total nilai yang diperoleh sebesar 0,79 lebih kecil dari 0,81. memberikan pengertian bahwa kondisi lingkungan pada kegiatan Posdaya bidang pendidikan dianggap belum mampu memberikan respon yang positif dalam setiap pelaksanaan kegiatan Posdaya bidang pendidikan. Hal ini bisa disebabkan karena peluang yang ada belum dapat dimanfaatkan secara maksimal untuk meminimalisir ancaman.
Berdasarkan hasl analisis diperoleh nilai IFAS 0,84 dan nilai EFAS sebesar 0,79. Dari hasil tersebut dapat dilihat letak posisi kegiatan Posdaya bidang pendidikan pada analisis SWOT di bawah ini.

Tabel 6. Hasil Matriks EFAS Kinerja Posdaya Bidang Pendidikan

$\begin{array}{lccc}\text { No } \begin{array}{l}\text { Faktor-Faktor Strategis } \\ \text { Eksternal }\end{array} & \text { Bobot } & \text { Rating } & \text { Nilai } \\ \begin{array}{l}\text { Peluang (Opportunities) } \\ \text { Peningkatan kapasitas SDM }\end{array} & & & \\ \text { masyarakat } & 0,11 & 5 & 0,55 \\ \begin{array}{l}\text { Bebas tiga buta (buta aksara, } \\ \text { buta angka, buta bahasa) }\end{array} & 0,11 & 5 & 0,56 \\ \begin{array}{l}\text { Pelatihan dan pengembangan } \\ \text { SDM }\end{array} & 0,11 & 5 & 0,56 \\ \text { Program kejar paket A (setara } & 0,10 & 4 & 0,39 \\ \text { SD) } & 0,11 & 5 & 0,55 \\ \text { Sumber dana beasiswa } & & & 2,62 \\ \text { Total Opportunities } & & & \\ \text { Ancaman (Threats) } & 0,09 & 4 & 0,38 \\ \text { Ketergantungan pada Pembina } & & & \\ \text { Semangat berlajar yang tidak } & 0,10 & 4 & 0,38 \\ \text { stabil } & 0,09 & 4 & 0,37 \\ \text { Karakter budaya instan } & 0,09 & 4 & 0,35 \\ \text { Tingkat pendidikan rendah } & 0,09 & 4 & 0,36 \\ \text { Fasilitas pendidikan minimalis } & 0,83 \\ \text { Total Threats } & & & 1,83 \\ \text { Selisih O - T } & & & 0,79\end{array}$

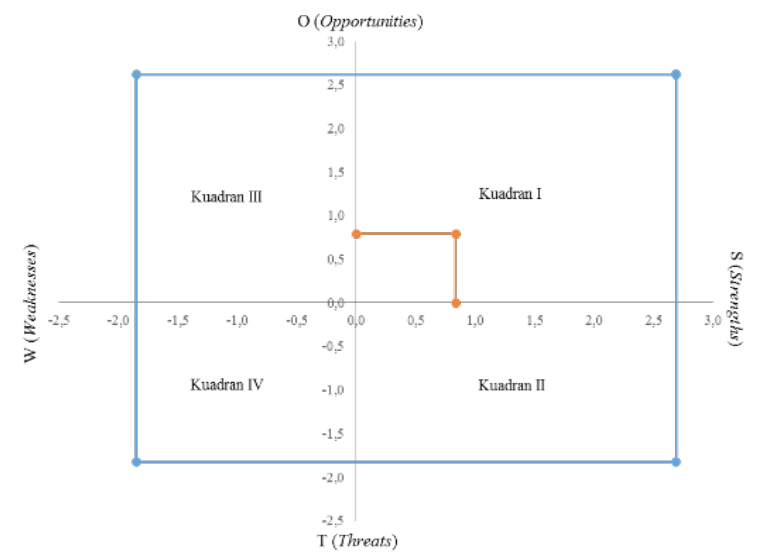

Gambar 2. Hasil Diagram Analisis SWOT Kinerja Posdaya Bidang Pendidikan

Dilihat dari Gambar 2, posisi kegiatan Posdaya bidang pendidikan berada pada kuadaran I, hal ini menunjukkan bahwa saat ini kondisi kegiatan Posdaya pada bidang pendidikan menggambarkan kondisi yang sangat mengun-tungkan yaitu kondisi internal yang kuat dengan lingkungan yang mendukung, sehingga arah, sasaran dan strategi kegiatan Posdaya bidang pendidikan yang sesuai adalah yang bersifat agresif, misalnya strategi pertumbuhan (growth strategy) dengan terus melakukan ekspansi, memperbesar pertumbuhan dan meraih kemajuan program-program pendidikan Posdaya secara maksimal. 
Analisis Kinerja BidangKesehatan

Berikut disajikan matriks IFAS dan EFAS kegiatan Posdaya bidang kesehatan seperti pada Tabel 7 dan 8 berikut.

\section{Tabel 7. Hasil Matriks IFAS Kinerja Posdaya Bidang Kesehatan}

\begin{tabular}{|c|c|c|c|c|}
\hline \multirow[t]{2}{*}{ No } & $\begin{array}{l}\text { Faktor-Faktor Strategis } \\
\text { Internal }\end{array}$ & Bobot & Rating & Nilai \\
\hline & \multicolumn{4}{|l|}{ Kekuatan (Strenghts) } \\
\hline & $\begin{array}{l}\text { Mengontrol kesehatan setiap } \\
\text { bulan, sakit atau tidak sakit }\end{array}$ & 0,12 & 5 & 0,59 \\
\hline & $\begin{array}{l}\text { Program rutin pusat layanan; } \\
\text { Posbindu, Posyandu, BKB }\end{array}$ & 0,12 & 5 & 0,59 \\
\hline & $\begin{array}{l}\text { Pemeriksaan kesehatan } \\
\text { tanpa biaya, hanya infak }\end{array}$ & 0,12 & 5 & 0,59 \\
\hline & $\begin{array}{l}\text { Sarana pemeriksaan tensi } \\
\text { darah secara rutin }\end{array}$ & 0,12 & 5 & 0,58 \\
\hline & Pelayanan kesehatan 24 jam & 0,11 & 5 & 0,54 \\
\hline & Total Strenghts & & & 2,89 \\
\hline \multicolumn{5}{|c|}{ Kelemahan (Weakness) } \\
\hline & $\begin{array}{l}\text { Tidak ada jaminan } \\
\text { kesehatan }\end{array}$ & 0,08 & 3 & 0,25 \\
\hline & Lebih percaya pada mistis & 0,07 & 3 & 0,21 \\
\hline & $\begin{array}{l}\text { Pola konsumsi pangan yang } \\
\text { tidak berimbang }\end{array}$ & 0,09 & 4 & 0,35 \\
\hline & Fasilitas olahraga tidak ada & 0,09 & 4 & 0,36 \\
\hline & $\begin{array}{l}\text { Tidak terampil mengolah } \\
\text { tanaman obat }\end{array}$ & 0,09 & 4 & 0,37 \\
\hline & Total Weakness & & & 1,53 \\
\hline & Selisih S - W & & & 1,36 \\
\hline
\end{tabular}

Tabel 8. Hasil Matriks EFAS Kinerja Posdaya Bidang Kesehatan

\begin{tabular}{|c|c|c|c|c|}
\hline No & $\begin{array}{c}\text { Faktor-Faktor Strategis } \\
\text { Eksternal }\end{array}$ & Bobot & Rating & Nilai \\
\hline & \multicolumn{4}{|l|}{ Peluang (Opportunities) } \\
\hline & $\begin{array}{l}\text { Pelayanan kesehatan di } \\
\text { tempat }\end{array}$ & 0,11 & 5 & 0,57 \\
\hline & Obat-obatan murah & 0,12 & 5 & 0,59 \\
\hline & $\begin{array}{l}\text { Keberadaan bidan/dokter } \\
\text { secara rutin }\end{array}$ & 0,11 & 5 & 0,57 \\
\hline & $\begin{array}{l}\text { Adanya proses pembelaja- } \\
\text { ran, seperti Kelas Gizi, PMT }\end{array}$ & 0,11 & 5 & 0,56 \\
\hline & $\begin{array}{l}\text { Memberi input/masukan } \\
\text { dalam hal kesehatan }\end{array}$ & 0,11 & 5 & 0,53 \\
\hline & Total Opportunities & & & 2,82 \\
\hline & \multicolumn{4}{|l|}{ Ancaman (Threats) } \\
\hline & Subsidi pemerintah rendah & 0,09 & 4 & 0,35 \\
\hline & $\begin{array}{l}\text { Aksesibilitas pada pe- } \\
\text { layanan yang rendah }\end{array}$ & 0,09 & 4 & 0,36 \\
\hline & $\begin{array}{l}\text { Tidak bisa akses informasi } \\
\text { program kesehatan }\end{array}$ & 0,08 & 3 & 0,24 \\
\hline & Budaya sehat yang rendah & 0,09 & 4 & 0,35 \\
\hline & Harga obat mahal & 0,09 & 4 & 0,38 \\
\hline & Total Threats & & & 1,67 \\
\hline & Selisih $\mathrm{O}-\mathrm{T}$ & & & 1,15 \\
\hline
\end{tabular}

Mengacu pada hasil perhitungan tersebut, dalam perhitungan strateginya memerlukan penegasan dari adanya posisi dalam salib sumbu yaitu antara kekuatan dan kelemahan, maupun peluang dan ancaman yang kesemuanya digambarkan dalam garis positif dan negatif. Hal ini mengakibatkan, skor total kekuatan tetap 2,89, skor total kelemahan menjadi -1,53 sedangkan skor total peluang 2.82, dan skor total ancaman menjadi -1,67. Dapat dicermati bahwaternyata faktor kekuatan lebih besar dari faktor kelemahan dan pengaruh dari faktor peluang lebih besar dari faktor ancaman. Kemudian diperoleh nilai IFAS sebesar 1,36 dan nilai EFAS sebesar 1,15 .

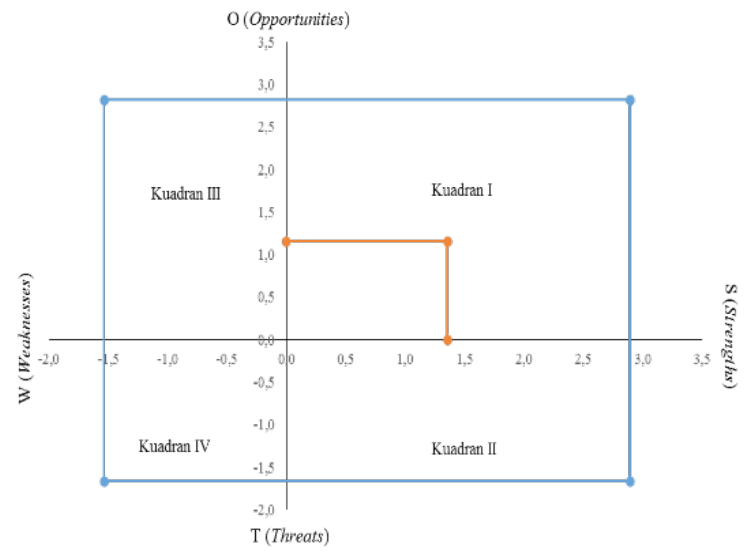

Gambar 3. Hasil Diagram Analisis SWOT Perkembangan Posdaya Bidang Kesehatan.

Oleh karena itu posisi kegiatan Posdaya bidang kesehatan berada pada kuadran 1 (Gambar 3) yang berarti pada posisi pertumbuhan, dimana hal ini menunjukkan kondisi internal kegiatan Posdaya bidang kesehatan yang kuat dengan peluang yang masih terbuka lebar dan kuat. Dilihat dari Gambar 3, posisi kegiatan Posdaya bidang kesehatan berada pada kuadran 1 dimana kegiatan bidang kesehatan pada kuadran ini dalam kondisi yang sangat menguntungkan, posisi tersebut juga menandakan sebuah kegiatan kesehatan yang kuat dan berpeluang.

Rekomendasi strategi yang diberikan adalah agresif, artinya kegiatan Posdaya bidang kesehatan ini dalam kondisi prima dan mantap sehingga sangat dimungkinkan untuk terus melakukan ekspansi, memperbesar pertumbuhan dan meraih kemajuan secara maksimal dengan kegiatan kesehatan lainnya yang kontinyu dan berkelanjutan. Kinerja Posdaya yang sudah cukup baik pada bidang kesehatan, dapat direplikasi pada Posdaya lainnya yang belum mencapai kinerja yang baik pada bidang ini.

\section{Analisis Kinerja BidangLingkungan}

Berikut disajikan matriks IFAS dan EFAS kegiatan Posdaya bidang lingkungan seperti pada Tabel 9 dan 10 berikut. 
Tabel 9. Hasil Matriks IFAS Kinerja Posdaya Bidang Lingkungan

\begin{tabular}{|c|c|c|c|c|}
\hline No & $\begin{array}{l}\text { Faktor-Faktor Strategis } \\
\text { Internal }\end{array}$ & Bobot & Rating & Nilai \\
\hline \multicolumn{5}{|c|}{ Kekuatan (Strenghts) } \\
\hline & $\begin{array}{l}\text { Semangat gotong royong } \\
\text { dan keswadayaan }\end{array}$ & 0,12 & 5 & 0,62 \\
\hline & Jaringan kemitraan Posdaya & 0,12 & 5 & 0,62 \\
\hline & $\begin{array}{l}\text { Program kompos dan } \\
\text { biopori }\end{array}$ & 0,12 & 5 & 0,59 \\
\hline & $\begin{array}{l}\text { Program penanganan } \\
\text { sampah rumah tangga }\end{array}$ & 0,12 & 5 & 0,61 \\
\hline & Total Strenghts & & & 2,43 \\
\hline & \multicolumn{4}{|l|}{ Kelemahan (Weakness) } \\
\hline & $\begin{array}{l}\text { Sarana dan prasarana pem- } \\
\text { berdayaan seadanya }\end{array}$ & 0,10 & 4 & 0,39 \\
\hline & $\begin{array}{l}\text { Belum memiliki gedung } \\
\text { serba guna sebagai pusat } \\
\text { aktivitas }\end{array}$ & 0,11 & 4 & 0,43 \\
\hline & $\begin{array}{l}\text { Belum adanya tempat kegia- } \\
\text { tan usaha produktif }\end{array}$ & 0,10 & 4 & 0,41 \\
\hline & $\begin{array}{l}\text { Anggapan Posdaya sebagai } \\
\text { proyek }\end{array}$ & 0,10 & 4 & 0,39 \\
\hline & $\begin{array}{l}\text { Kelompok peduli lingkun- } \\
\text { gan rendah }\end{array}$ & 0,11 & 4 & 0,43 \\
\hline & Total Weakness & & & 2,06 \\
\hline & Selisih S - W & & & 0,37 \\
\hline
\end{tabular}

Tabel 10. Hasil Matriks EFAS Kinerja Posdaya Bidang Lingkungan

\begin{tabular}{|c|c|c|c|c|}
\hline No & $\begin{array}{c}\text { Faktor-Faktor Strategis } \\
\text { Eksternal }\end{array}$ & Bobot & Rating & Nilai \\
\hline \multicolumn{5}{|c|}{ Peluang (Opportunities) } \\
\hline & $\begin{array}{l}\text { Gaya hidup yang kembali } \\
\text { ke alam }\end{array}$ & 0,10 & 4 & 0,41 \\
\hline & $\begin{array}{l}\text { Banyaknya lembaga pro } \\
\text { penghijauan }\end{array}$ & 0,10 & 2 & 0,20 \\
\hline & $\begin{array}{l}\text { Program pemerintah dalam } \\
\text { menghindari bencana alam }\end{array}$ & 0,10 & 2 & 0,21 \\
\hline & $\begin{array}{l}\text { Pengembangan agrowisata } \\
\text { dan ekowisata }\end{array}$ & 0,09 & 3 & 0,28 \\
\hline & $\begin{array}{l}\text { Kompetisi kebersihan } \\
\text { lingkungan }\end{array}$ & 0,10 & 3 & 0,31 \\
\hline & Isu global warming & 0,08 & 2 & 0,17 \\
\hline & Total Opportunities & & & 1,57 \\
\hline \multicolumn{5}{|c|}{ Ancaman (Threats) } \\
\hline & $\begin{array}{l}\text { Aksesibilitas informasi } \\
\text { rendah }\end{array}$ & 0,08 & 5 & 0,42 \\
\hline & $\begin{array}{l}\text { Lemahnya inistiatif dan } \\
\text { budaya berkumpul }\end{array}$ & 0,09 & 5 & 0,45 \\
\hline & $\begin{array}{l}\text { Instabilitas politik pusat dan } \\
\text { atau daerah }\end{array}$ & 0,07 & 4 & 0,29 \\
\hline & $\begin{array}{l}\text { Narsisnya lembaga-lembaga } \\
\text { pembina masyarakat yang } \\
\text { telah eksis }\end{array}$ & 0,07 & 4 & 0,30 \\
\hline & $\begin{array}{l}\text { Rendahnya dukungan aparat } \\
\text { wilayah di lingkungan } \\
\text { Posdaya }\end{array}$ & 0,09 & 5 & 0,46 \\
\hline & Total Threats & & & 1,92 \\
\hline & Selisih $\mathrm{O}-\mathrm{T}$ & & & $-0,34$ \\
\hline
\end{tabular}

Dari analisis tersebut di atas bahwasanya faktor kekuatan lebih besar dari faktor kelemahan dan pengaruh dari faktor peluang lebih besar dari faktor ancaman. Kemudian diperoleh nilai IFAS sebesar 0,37 dan nilai EFAS sebesar -0,34. Oleh karena itu posisi kegiatan Posdaya bidang lingkungan berada pada kuadran 2 (Gambar 4) yang berarti pada posisi kombinasi, dimana hal ini menunjukkan kondisi internal kegiatan Posdaya bidang lingkungan yang kuat namun dihadapkan pada ancaman yang kuat juga.

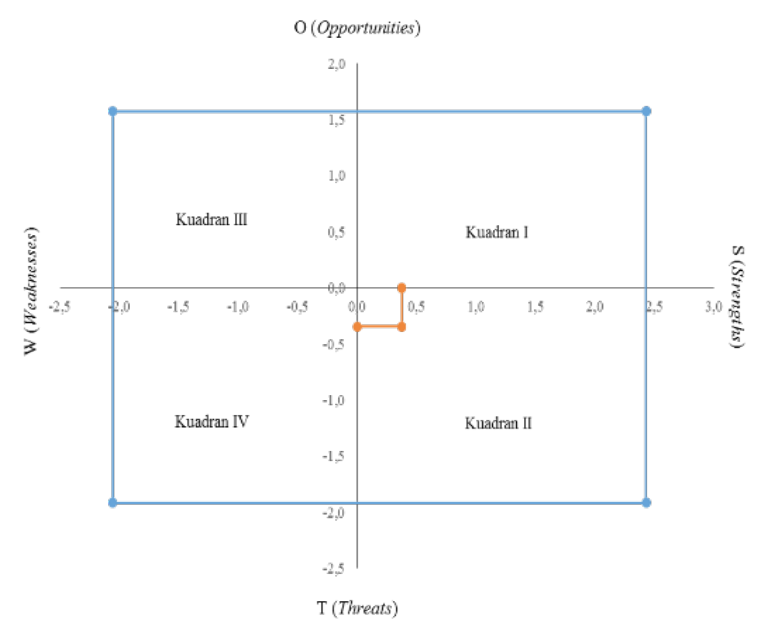

Gambar 4. Hasil Diagram Analisis SWOT Kinerja Posdaya Bidang Lingkungan.

Berdasarkan Gambar 4, posisi kegiatan Posdaya bidang lingkungan berada pada kuadran 2 dimana kondisi pelaksanaan kegiatan Posdaya bidang lingkungan ini meskipun menghadapi ancaman, namun kondisi kegiatan ini masih memiliki kekuatan dari segi internal.

Oleh karena itu pada kegiatan Posdaya bidang lingkungan harus memanfaatkan kekuatan internalnya dengan maksimal untuk mengatasi berbagai ancaman yang dihadapinya dan disarankan untuk segera memperbanyak ragam strategi taktisnya atau strategi untuk bidang lingkungan yang sesuai adalah yang bersifat defensif, misalnya mempertahankan eksistensi (survival strategy).

Berdasarkan hasil analisis SWOT dengan matriks IFAS dan EFAS terhadap empat bidang kegiatan Posdaya,menunjukkan bahwa faktor-faktor pendukung dan penghambat perkembangan Posdaya pada bidang ekonomi masih memiliki kelemahan walaupun peluang yang diberikan oleh lingkungan eksternal juga cukup tinggi. Pada bidang pendidikan menggambarkan kondisi yang sangat menguntungkan yaitu kondisi internal yang kuat dengan lingkungan yang mendukung, pada bidang kesehatan faktor pendukung dan penghambat menggambarkan kondisi yang sangat prima dan sangat menguntungkan yang ditandai kesehatan yang kuat dan berpeluang. Pada bidang lingkungan, faktor kelemahan dan pengaruh dari faktor peluang lebih besar dari faktor ancaman dimana kondisi pelaksanaan kegiatan Posdaya bidang lingkungan ini meskipun menghadapi ancaman, 
namun kondisi kegiatan ini masih memiliki kekuatan dari segi internal.

\section{SIMPULAN}

Simpulan yang diperoleh dari hasil kajian ini adalah bahwa kinerja Posdaya di wilayah Kota Bogor dan Kabupaten Bogor tergolong cukup baik, terutama dalam bidang kesehatan, kesekre-tariatan, pendidikan dan ekonomi. Sementara itu kinerja Posdaya dalam bidang kemitraan/kerjasama dan lingkungan masih tergolong kurang baik.

Perlu dilakukan pembinaan lebih lanjut terhadap Posdaya yang masih lemah kinerjanya, terutama pada bidang kemitraan/kerjasama dan lingkungan. Upaya pembinaan dapat dilakukan melalui kegiatan pelatihan dan pendampingan kepada pengurus dan kader Posdaya. Kegiatan pembinaan dapat melibatkan berbagai pihak seperti unsur perguruan tinggi, pemerintah daerah/kota, dan perusahaan swasta.

\section{UCAPAN TERIMA KASIH}

Tim peneliti mengucapkan terima kasih kepada para pengurus dan kader Posdaya di Kabupaten Bogor dan Kota Bogor, yang telah bersedia menjadi responden penelitian. Ucapan terima kasih disampaikan pula kepada Kementerian Pendidikan dan Kebudayaan RI yang telah memberikan dana untuk pelaksanaan penelitian ini.

\section{DAFTAR PUSTAKA}

Babbie, E. 1992. Practicing Social Research. $6^{\text {th }}$ Ed. Wadsworth Publishing Company. California.

Muljono, P. 2010. The Posdaya model for community empowerment. Journal of Community, Culture and Politics, 23(1), 9-16.

Muljono, P. 2011. The model of family empowerment program for community development in West Java, Indonesia. Journal of Agricultural Extension and Rural Development, 3(11), 193-201.
Muljono, P. 2012. Metode Penelitian Sosial. IPB Press. Bogor.

Muljono, P. 2013a. The role of Posdaya in shaping community empowerment: Case study at Cikarawang Village, Bogor, Indonesia. Asian Journal of Humanities and Social Studies, 01 (5), 225-232.

Muljono, P. 2013b. Replication of Posdaya for community empowerment programe: case study at Situgede Village, Bogor, Indonesia. Asian Journal of Humanities and Social Sciences, 01(3), 1-8.

Muljono, P., Burhanuddin \& Bachtiar, Y. 2009. Upaya pemberdayaan masyarakat dan pengentasan kemiskinan melalui model Posdaya. Laporan Penelitian. Kerjasama Dikti dan IPB. Bogor.

Sadono, D., Saharuddin \& Yusalina. 2014. Indeks kepuasan masyarakat terhadap program Posdaya. Kesejahteraan Sosial, 1(1), 1-12.

Saleh, A., Rokhani \& Bahtiar, R. 2014. Hubungan dukungan eksternal dan kewirausahaan terhadap modal sosial melalui model Posdaya di Kota Bogor, Kabupaten Bogor dan Cianjur. Kesejahteraan Sosial, 1(1), 25-38.

Suharto, E. 2005. Membangun masyarakat memberdayakan rakyat. Refika Aditama. Bandung.

Sumarjo \& Saharuddin. 2004. Metode-metode partisipatif dalam pengembangan masyarakat. Departemen Ilmu-Ilmu Sosial dan Ekonomi Fakultas Pertanian dan Program Pasca Sarjana IPB. Bogor.

Suwito, S. 2014. Efektivitas program pemberdayaan. Kesejahteraan Sosial, 1(1), 13-24.

Suyono, H. 2007. Mengentas kemiskinan, Makalah Seminar Nasional, Universitas Brawijaya. Malang.

Suyono, H. \&Haryanto, R. 2009. Buku pedoman pembentukan dan pengembangan pos pemberdayaan keluarga (Posdaya). Yayasan Dana Sejahtera Mandiri. Jakarta. 